\title{
RANCANG BANGUN MESIN PULPER KOPI MENGGUNAKAN PENGGERAK MOTOR LISTRIK
}

\section{DESIGN OF A COFFEE PULPER MACHINE USING AN ELECTRIC MOTOR}

\author{
Tri Ego Wiranata1, Ruzita Sumiati ${ }^{1}$, Rakiman$^{1}$, Yuli Yetri ${ }^{1 凶}$ \\ ${ }^{1}$ Program Studi D-III Teknik Mesin, Jurusan Teknik Mesin, Politeknik Negeri Padang \\ ${ }^{\bowtie}$ Komunikasi Penulis, email : yuliyetri@pnp.ac.id \\ DOI:http://dx.doi.org/10.23960/jtep-l.v10i1.26-32 \\ Naskah ini diterima pada 8 September 2020; revisi pada 8 Desember 2020; \\ disetujui untuk dipublikasikan pada 1 Februari 2021
}

\begin{abstract}
Design and manufacture of coffee pulper machines have been carried out with the aim of completing the needs of the coffee farmer groups when harvesting in the Kayu Aro area, Kerinci. The steps in designing and manufacturing a coffee pulper begins with a literature study, design and calculation, the process of making the tool and ends with testing the tool. Engineering drawing design is done by modeling in SolidWorks software. Coffee peeler machine with a capacity of $4 \mathrm{~kg} / \mathrm{min}$, with a machine size of $730 \mathrm{~mm} \times 320 \mathrm{~mm} \times 1040 \mathrm{~mm}$, using an electric motor $1 \mathrm{HP}$ $1420 \mathrm{rpm}$, with a frame using an elbow profile $40 \mathrm{~mm} \times 40 \mathrm{~mm} \times 3 \mathrm{~mm}$. The transmission system uses an electric motor with an initial rotation of $1420 \mathrm{rpm}$ to $364.6 \mathrm{rpm}$. In the 2 pulley component $D=74.6 \mathrm{~mm}$ and $290.5 \mathrm{~mm}$, $V$-belt type $B$ No.52, 1 solid shaft $D=25 \mathrm{~mm}$. Initial test results using 2-5 kg of wet coffee beans take 30.07-77.20 seconds, and the skin has separated from the beans cleanly. These results show that the engine capacity is 235.62 $\mathrm{kg} / \mathrm{h}$, so that the desired target is met with relatively low operating costs. The existence of this tool will be able to help the process of separating the skin and coffee beans, so that the quality of coffee production will increase.
\end{abstract}

Keywords: coffee, coffee machine, design and construction, farmer groups

\begin{abstract}
ABSTRAK
Telah dilakukan perancangan dan pembuatan mesin pengupas kulit kopi dengan tujuan guna melengkapi keperluan kelompok petani kopi ketika panen di daerah Kayu Aro, Kerinci. Langkah-langkah dalam perancangan dan pembuatan mesin pengupas kulit kopi diawali dengan studi literatur, perancangan dan perhitungan, proses pembuatan alat dan diakhiri dengan pengujian alat. Desain gambar teknik dilakukan dengan modeling pada software solidworks. Mesin pengupas kulit kopi berkapasitas $4 \mathrm{~kg} /$ menit, dengan ukuran mesin 730 mm x 320 $\mathrm{mm}$ x $1040 \mathrm{~mm}$, memakai motor listrik $1 \mathrm{HP} 1420 \mathrm{rpm}$, dengan rangka memakai profil siku $40 \mathrm{~mm}$ x $40 \mathrm{~mm}$ x $3 \mathrm{~mm}$. Sistem transmisi memakai motor listrik dengan putaran awal $1420 \mathrm{rpm}$ menjadi 364,6 rpm. Pada komponen 2 puli $\mathrm{D}=74,6 \mathrm{~mm}$ dan 290,5 mm, V-belt jenis B No.52, 1 poros pejal $\mathrm{D}=25 \mathrm{~mm}$. Hasil pengujian awal alat menggunakan 2-5 kg biji kopi basah diperlukan waktu selama 30,07-77,20 detik, dan kulit sudah terpisah dari biji dengan bersih. Hasil tersebut menunjukan bahwa kapasitas mesin adalah 235,62 kg/jam, sehingga target yang diinginkan terpenuhi dengan biaya pengoperasian relatif murah. Keberadaan alat ini akan dapat membantu proses pemisahan kulit dan biji kopi, sehingga kualitas produksi kopi akan meningkat.
\end{abstract}

Kata Kunci: kelompok tani, kopi, mesin kopi, rancang bangun

\section{PENDAHULUAN}

Kopi merupakan minuman yang terpopuler nomor 2 di jagad raya setelah teh. Bagi sebagian orang, meminum kopi bukan hanya sebagai selingan tetapi sudah merupakan bagian dari gaya hidup (Sabani, 2018). Bagi masyarakat Indonesia kopi merupakan minuman favorit baik dari kalangan atas maupun kalangan bawah, dan bahkan juga digemari oleh pria maupun wanita.

Di Indonesia terdapat berbagai jenis kopi dengan ciri khas dan cita rasa serta ukuran kopi yang beraneka ragam. Jenis kopi yang beredar luas adalah Arabika, Robusta, dan Liberika (Amran 
et al., 2017; Nasution dan Efendi, 2018). Begitu juga wilayah Kerinci sebagai daerah sentra penghasil kopi di Indonesia. Kopi Arabika Kerinci dengan ciri biji kopi berbentuk bulat dan tumbuh baik pada ketinggian $700-1.200$ meter dari di atas permukaan laut pada suhu $19-25^{\circ} \mathrm{C}$. Biji kopi mentah berwarna hijau dan ketika matang berubah menjadi merah, dengan periode kematangan buah antara 9-10 bulan (Sabani, 2018; Nasution dan Efendi, 2018).

Walaupun saat ini biji kopi sebagai salah satu komoditi yang sedang berkembang (Sabani, 2018; Amran et al, 2017), tetapi banyak masalah yang dialami oleh para pengusaha kopi di daerah dalam meningkatkan usahanya. Hal ini disebabkan karena minimnya peralatan pendukung kelancaran usahanya (Sularso dan Suga, 1997; Ahmad, 2016). Di daerah Kerinci, petani kopi saat ini masih menggunakan peralatan manual dalam proses pengolahan kopi. Dari hasil produksi sekitar $200 \mathrm{~kg} / \mathrm{hari}$, hingga proses mengupas dan memisahkan biji dan kulit kopi sulit dilakukan dan memakan waktu cukup lama dalam pengerjaannya (Sabani, 2018; Amran et al., 2017).

Seiring dengan program pemerintah untuk menggalakkan hasil-hasil produk pertanian, khususnya kopi, maka diperlukan teknologi mesin-mesin pertanian untuk menunjang program tersebut (Darmawan dan Harsokusoemo, 2004). Kemajuan teknologi, dan perkembangan mesin-mesin untuk proses produksi juga berkembang sangat cepat (Sugandi et al, 2017). Mesin tersebut sangat bermanfaat untuk membantu proses pengerjaan yang dilakukan agar lebih mudah dan menghemat waktu, tetapi tidak dapat dipindah, sehingga penggunaannya terbatas di tempat tertentu. Hal seperti ini tidak dapat dipungkiri dalam produksi biji kopi, karena selama ini proses pemisahan biji dari kulit dilakukan setelah kering, dan biasanya dilakukan di tempat tertentu. Dengan kemajuan ilmu pengetahuan ternyata pemisahan biji dari kulit dalam keadaan baru dipetik dapat memberikan aroma lebih baik dari pada dalam keadaan kering (Sabani, 2018; Sodik et al., 2016). Kondisi seperti itu memungkinkan untuk melakukan pemisahan dikebun habis dipetik, sehingga butuh alat yang praktis untuk mudah dibawa-bawa. Pemisahan lain yang berkembang saat ini adalah pemisahan berdasarkan kecepatan terminal (terminal velocity). Cara pemisahan ini biasanya diterapkan pada biji-bijian untuk memisahkan biji dengan pengotor yang massa jenisnya berbeda (Sutejo et al., 2018).

Bertolak dari masalah yang sudah diuraikan di atas, maka perlu dibuat alat atau mesin pulper kopi dengan memadukan beberapa sumber. Langkah berikutnya adalah uji fungsional untuk memastikan mesin tersebut berjalan dengan baik. Uji kinerja mesin dilakukan setelah uji fungsional dianggap sesuai dengan hasil rancangan yang meliputi, kapasitas mesin, daya daya mesin, dan uji performansi (Sugandi et al., 2017). Keberadaan alat ini mudah untuk dibawa sehingga mampu meningkatkan jumlah produksi kopi dengan proses yang lebih mudah dan efisien untuk hasil yang lebih maksimal. Tujuan dari pembuatan alat ini adalah untuk mendesain alat pengupas kopi basah yang dapat mempermudah petani kopi dalam memisahkan biji dan kulit kopi yang baru dipetik. Alat didesain agar dapat bekerja cepat sehingga tidak membutuhkan waktu yang lama untuk mengeringkan biji kopi yang telah terpisah dari kulitnya, serta untuk mengurangi biaya operasional akibat penggunaan bahan bakar minyak.

\section{BAHAN DAN METODE}

Alat ini dirancang dan dibuat pada bulan Juni sampai September 2019, yang dikerjakan di laboratorium Teknologi Mekanik, Jurusan Mesin, Politeknik Negeri Padang. Serangkaian kegiatan yang dilakukan dalam pembuatan alat ini dapat dilihat pada Gambar 1 .

Pembuatan mesin memerlukan bahan bahan baja ST 42 , baja profil L, poros, pelat besi, pipa stainless, bearing, motor penggerak, baut dan mur, elektroda, puli, belt, dll. Peralatan yang digunakan untuk membuat alat ini terdiri dari mesin bubut, mesin las, mesin bor, mistar, penggores, ragum, gerinda tangan.

\subsection{Desain Rancangan}

Desain rancangan alat ini konsepnya dibuat menggunakan software Autocad 2007, dan hasilnya dapat dilihat pada Gambar 2. 


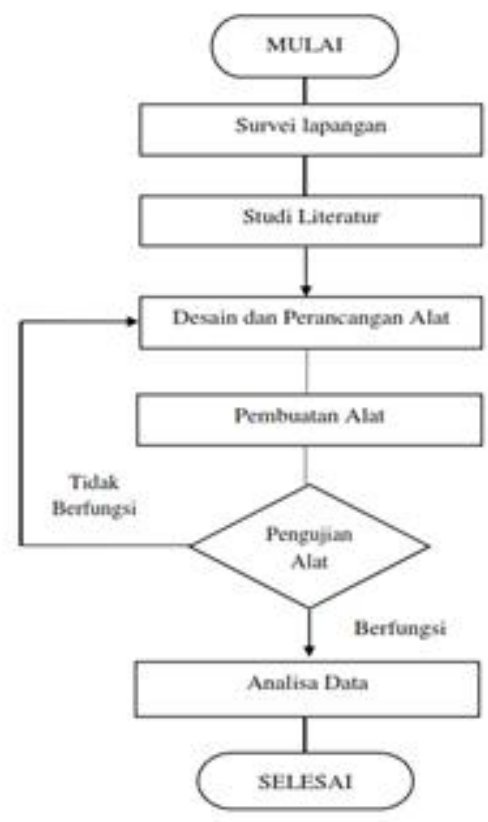

Gambar 1. Diagram Alir Proses

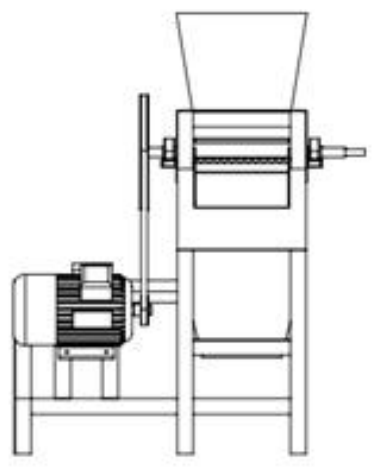

a

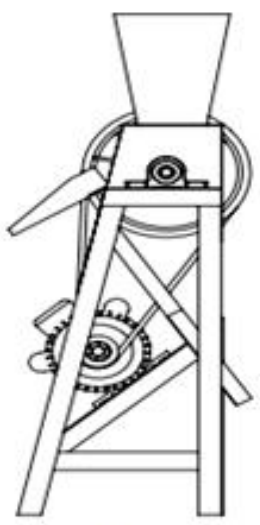

b

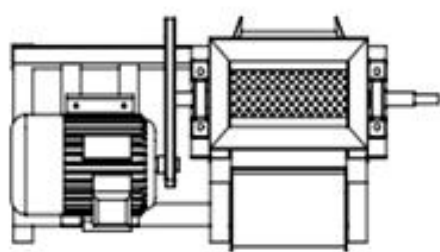

c

Gambar 2. Desain Alat Coffee Pulper: (a) Tampak Depan, (b) Tampak Samping, dan (c) Tampak Atas

\subsection{Perhitungan Komponen}

\subsubsection{Menghitung Poros}

Bahan untuk poros dipilih baja ST 42 dengan kekuatan tarik $\sigma_{\mathrm{b}}=42 \mathrm{~kg} / \mathrm{mm}^{2}$ atau $412,02 \mathrm{~N} /$ $\mathrm{mm}^{2}$, dengan $S f_{1}$ (faktor keamanan bahan) adalah 5,6-6,0 dan $S f_{2}$ (faktor tumbukan bahan) adalah 1,3-3,0. Berdasarkan kajian literatur (Sularso dan Suga, 1997; Ahmad, 2016; Sodik, 2016) perencanaan poros dihitung sebagai berikut.

\section{a. Rencana daya (Pd)}

Daya yang ditransmisikan $P$ adalah $1 \mathrm{hp}$ atau $0,745 \mathrm{~kW}$ dengan putaran motor $n_{1}=1420 \mathrm{rpm}$. Rencana daya $(P d)$ dihitung dari Persamaan 1 dengan faktor koreksi $(F C)$ 2,0 sehingga diperoleh $P d=1,47 \mathrm{~kW}$.

$$
\mathrm{Pd}=\mathrm{Fc} \times \mathrm{P}
$$

\section{b. Momen puntir (T)}

Momen puntir ( $T$ ) dihitung dari Persamaan 2 dan diperoleh $T=1008,29$ kg.mm:

$$
T=9,74 \times 10^{5} \times \frac{P d}{n_{1}}
$$

\section{c. Tegangan geser}

Tegangan geser $\left(\tau_{a}\right)$ yang diizinkan dihitung menggunakan Persamaan 3:

$$
\tau_{a}=\frac{\sigma_{b}}{S f_{1} \times S f_{2}}
$$


dimana $\mathrm{s}_{b}=42 \mathrm{~kg} / \mathrm{mm}^{2}, S_{\mathrm{f} 1}=6,0$, dan $S_{\mathrm{f} 2}=3,0$, sehingga diperoleh $\mathrm{t}_{a}=2,3 \mathrm{~kg} / \mathrm{mm}^{2}$.

\section{d. Diameter poros $\left(d_{s}\right)$}

Diameter poros $\left(d_{s}\right)$ dihitung dari Persamaan 4 dan diperoleh $d_{s}=25 \mathrm{~mm}$

$$
d_{s}=\left(\frac{5,1}{\tau_{a}} \times K t \times C b \times T\right)^{1 / 3}
$$

dimana $K t=$ faktor koreksi akibat momen puntir $(K t=3,0), C b=$ faktor koreksi akibat momen lentur $(C b=2,3$. Jika tidak terjadi pembebanan lentur maka nilai $C b=1,0$ ).

\subsubsection{Perencanaan Transmisi}

\section{a. Puli}

Putaran poros puli dihitung dari perbandingan putaran poros motor dan poros puli besar (Darmawan, 2004; Sularso dan Suga, 1997):

$$
\frac{n_{1}}{n_{2}}=\frac{D_{b}}{d_{b}}
$$

dengan diameter puli motor $d_{b}=74,6 \mathrm{~mm}$ dan diameter puli besar $D_{b}=290,5 \mathrm{~mm}$, maka putaran poros puli $n_{2}$ dapat dihitung menjadi $364,65 \mathrm{rpm}$.

Parameter $D_{p}$ (jarak puli besar), $d_{k}$ (diameter luar puli kecil), dan $D_{k}$ (diameter luar puli besar) dihitung dengan cara sebagai berikut:

$$
D_{p}=\frac{n_{1}}{n_{2}} \times d_{p}
$$

Dengan $\mathrm{n}_{1}=1420 \mathrm{rpm}, \mathrm{n}_{2}=364,6 \mathrm{rpm}$, dan $d_{\mathrm{p}}=$ $290,5 \mathrm{~cm}$, akan diperoleh $D_{\mathrm{p}}=1131,7 \mathrm{~mm}$.

$$
\begin{aligned}
& d_{\mathrm{k}}=d_{\mathrm{b}}+(2 \times 5,5)=85,6 \mathrm{~mm} \\
& D_{\mathrm{k}}=D_{\mathrm{b}}+(2 \times 5,5)=301,5 \mathrm{~mm}
\end{aligned}
$$

\section{b. Kecepatan Sabuk-V}

Kecepatan Sabuk-V ( $v$ ) dihitung dari Persamaan 7 dan didapatkan $\mathrm{v}=5,54 \mathrm{~m} / \mathrm{s}$.

$$
V=\frac{\pi \times d_{p} \times n_{1}}{60 \times 1000}
$$

\section{c. Panjang sabuk $(L)$}

Panjang sabuk $(L)$ dihitung dari Persamaan 8 dan didapatkan $L=1306,5 \mathrm{~mm}$.

$$
L=2 C\left(\frac{\pi}{2}\right)\left(D_{p}+d_{p}\right)+\frac{1}{4 C}\left(D_{p}-d_{p}\right)^{2}
$$

dimana $\mathrm{C}=350 \mathrm{~mm}$ adalah jarak sumbu poros. Dalam hal ini dapat dipilih Sabuk-V nomor B52 yang memiliki panjang $L 1321 \mathrm{~mm}$.

\section{d. Jarak Sumbu Poros $(C)$}

Jarak sumbu poros $(C)$ dihitung menggunakan Persamaan 9 (Sularso dan Suga, 1997).

$$
C=\frac{b+\sqrt{b^{2}-8\left(D_{p}-d_{p}\right)^{2}}}{8}
$$

dimana $b$ adalah konstanta puli motor dan puli besar, dan dihitung dari:

$$
b=2 L-\pi\left(D_{p}+d_{p}\right)=1495,59 \mathrm{~mm} .
$$

Dengan memasukkan nilai-nilai yang ada akan diperoleh jarak sumbu poros $C=357,6 \mathrm{~mm}$.

\section{e. Sudut kontak}

Sudut kontak $(\theta)$ dihitung dari Persamaan 11 dan diperoleh $\theta=145^{\circ}$. Menurut Sonawan (2010), faktor koreksi $\left(K_{\theta}\right)$ untuk $\theta=145^{\circ}$ adalah 0,91 .

$$
\theta=180^{\circ}-\frac{57\left(D_{p}-d_{p}\right)}{C}
$$

\subsection{Pengujian}

Mesin hasil rancangan diuji tiga kali dengan beban penggilingan kopi: $2 \mathrm{~kg}, 3 \mathrm{~kg}$, dan $5 \mathrm{~kg}$. Lama pengupasan dicatat untuk menghitung kapasitas kerja alat. Selain kecepatan alat, hasil pemisahan antara biji dan kulit kopi juga diamati untuk melihat apakah selama proses pencucian biji kopi terdapat banyak kulit yang tercampur dengan biji kopi.

\section{HASIL DAN PEMBAHASAN}

\subsection{Prinsip Kerja Alat}

Prinsip kerja mesin pengupas kulit kopi mengandalkan putaran motor penggerak untuk memutar poros pada rol penggilas. Kopi yang masuk ke dalam hopper terbawa oleh putaran penggilas dan terjadi penjepitan buah kopi antara penggilas dengan besi penahan. Setelah kopi terpecah maka biji dan kulit kopi terpisah dengan sendirinya dan keluar melalui tempat keluar masing-masing.

\subsection{Komponen Pada Mesin Pulper Kopi}

Rancangan mesin pulper kopi ditunjukkan pada Gambar 3 dan spesifikasi diringkaskan pada 
Tabel 1. Fungsi dari masing-masing komponen mesin pulper kopi (Gambar 3) adalah sebagai berikut:

1. Rangka: untuk penopang semua komponen mesin ini.

2. Hopper: untuk tempat masuknya buah kopi dan sebagai penampung buah kopi yang akan diproses.

3. Poros: untuk tempat penggilas dan untuk meneruskan putaran yang berasal dari motor penggerak yang dihubungkan melalui puli dan sabuk penghubung.

4. Penggilas : untuk menggilas atau menjepit buah kopi agar dapat terpecah sehingga biji dan kulit kopinya terpisah.

5. Motor listrik: sebagai tenaga penggerak untuk menggerakkan poros pada penggilas agar dapat berputar.

6. Outer biji kopi: sebagai tempat keluarnya biji kopi yang telah diproses.

7. Outer kulit kopi: sebagai tempat keluarnya kulit kopi yang telah diproses.

8. Bodi depan: sebagai tutup bodi pada bagian depan mesin pulper kopi ini.

9. Bantalan/bearing: sebagai tempat tumpuan poros dan untuk memperlancar putaran pada poros agar menjadi lebih halus.

10.Puli: sebagai penghubung pada gigi pengupas dan sebagai bagian yang digerakkan oleh sabuk yang menghubungkan kedua puli agar dapat berputar.

11.Sabuk: untuk meneruskan putaran yang terhubung melalui puli yang berasal dari motor penggerak ke puli poros yang digerakkan agar dapat berputar.

\subsection{Mesin Pulper Hasil Rancang Bangun}

Dari rancangan yang telah dilakukan, maka selanjutnya dilakukan proses pembuatan alat. Alat yang dihasilkan tersebut seperti terlihat pada Gambar 4.

\subsection{Kapasitas Alat}

Mesin pengupas kulit kopi basah berfungsi untuk memisahkan biji kopi dari kulitnya. Agar fungsi utama terpenuhi maka diperlukan fungsi penunjang yaitu penggilas yang presisi, hopper, tempat keluar hasil pemisah dan rangka bodi mesin yang dirancang khusus dengan mempertimbangkan faktor ergonomi.

\section{a. Pengukuran Kapasitas Mesin}

Kapasitas merupakan kemampuan kerja mesin mengolah bahan per satuan waktu (Sonawan, 2010).

$$
\mathrm{Ka}=\frac{W p}{t}
$$

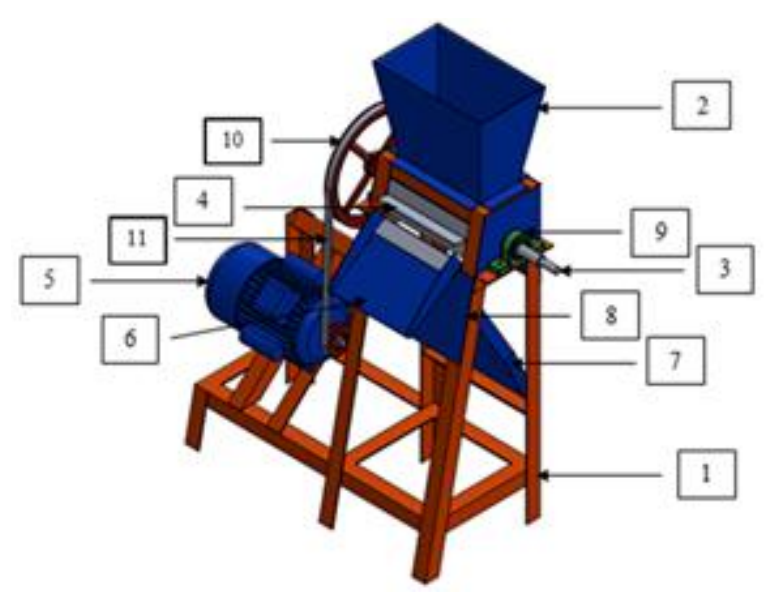

Gambar 3. Komponen Mesin Pulper Kopi

Tabel 1. Spesifikasi Mesin Pulper Kopi

\begin{tabular}{ll}
\hline Nama & Pulper Kopi \\
\hline Type & Penggerak Motor Listrik \\
Kapasitas & $235 \mathrm{~kg} /$ jam \\
Dimensi & $72,9 \times 32 \times 103 \mathrm{~cm}$ \\
Listrik & $745 \mathrm{Watt}(1 \mathrm{HP}), 220 \mathrm{~V}$
\end{tabular}




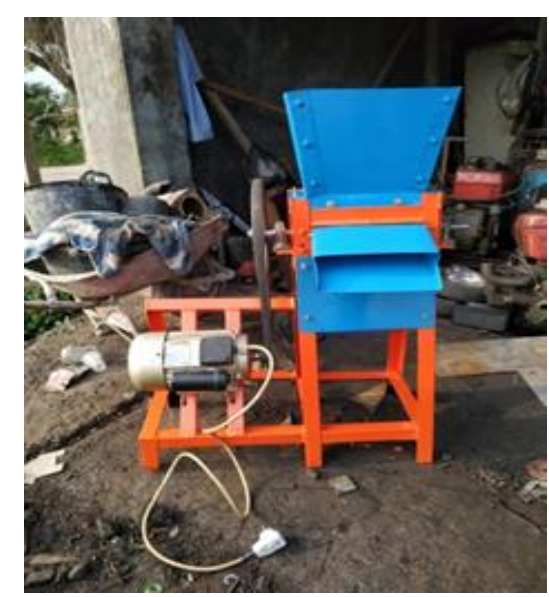

Gambar 4. Hasil Alat Mesin Pulper Kopi

Tabel 2. Kapasitas Alat Coffee Pulper

\begin{tabular}{ccc}
\hline Beban Uji (kg) & Waktu (detik) & Kapasitas (kg/jam) \\
\hline 2 & 30,07 & 239,44 \\
3 & 46,10 & 234,27 \\
5 & 77,20 & 233,16 \\
\hline \multicolumn{3}{r}{ Rata-rata } \\
\hline
\end{tabular}

dimana Ka adalah kapasitas aktual (kg/jam), $W p$ adalah berat total buah kopi yang masuk ke mesin (kg), $t$ adalah waktu yang dibutuhkan untuk pengupasan (jam).

Alat pengupas kulit kopi basah ini, diuji sebanyak $3 \mathrm{X}$ dengan kapasitas $2 \mathrm{~kg}, 3 \mathrm{~kg}$, dan $5 \mathrm{~kg}$ buah kopi dan membutuhkan waktu 30,07 detik, 46,10 detik, dan 77,20 detik untuk mengupasnya. Maka kapasitas alat dihitung dari Persamaan 11 dan hasilnya diberikan pada Tabel 2 . Jadi alat ini dalam waktu 1 jam dapat mengupas kopi sebanyak sebanyak 235,62 kg. Jika produksi kopi sehari $500 \mathrm{~kg}$, maka dapat ditempuh dalam waktu 2 jam 7 menit.

\section{b. Biaya Penggunaan Motor Listrik}

Motor listrik yang digunakan yaitu motor listrik AC $1 \mathrm{Hp}$ atau 0,745 kW. Untuk tarif biaya penggunaan motor listrik tersebut dihitung per kWh. Penggunaan listrik rumah tangga dengan daya 1.300 VA untuk golongan R-1/TR. Dengan tarif pemakaian Rp.1.467,28/kWh, maka biaya penggunaan listrik adalah $1.093,12 \mathrm{Rp} / \mathrm{jam}$ atau $2.328,35 \mathrm{Rp} /$ hari. Dengan kapasitas 235,62 kg/ jam biaya listrik adalah 4,64 Rp/kg. Apabila mesin digunakan untuk $500 \mathrm{~kg}$ kopi basah, maka biaya yang dikeluarkan per hari yaitu Rp.2.319,67.
Berdasarkan fakta yang ada melalui wawancara langsung dengan pengusaha kopi Sumber Rizki Desa Batang Sangir, Kerinci, Jambi. Mesin pengupas kulit kopi dengan menggunakan penggerak engine bensin dalam waktu 1 jam menghabiskan bahan bakar sebanyak 1 liter. Untuk $500 \mathrm{~kg}$ mesin memerlukan bahan bakar minyak (BBM) sebanyak 2,117 liter, dan dengan BBM $8.000 \mathrm{Rp} / \mathrm{L}$, maka biaya BBM mencapai $33,87 \mathrm{Rp} / \mathrm{kg}$ atau $17.040 \mathrm{Rp} /$ hari.

Jadi bisa disimpulkan bahwa mesin menggunakan penggerak motor listrik lebih menghemat biaya 9 kali lipat dibandingkan dengan mesin menggunakan penggerak engine bensin. Serta mesin menggunakan motor listrik lebih ramah lingkungan daripada menggunakan engine bensin (Siswoyo, 2008; Effendi dan Khumaidi, 2018). Pernyataan ini sejalan dengan (Sudirman et al., 2014) menyatakan meningkatnya jumlah dan hematnya waktu ini jelas sangat membantu petani dibandingkan melakukan pembersihan gabah secara manual.

Maka dari itu penggunaan motor listrik sangat tepat dan sangat dianjurkan dalam pembuatan mesin ini. Selain lebih menghemat biaya, motor listrik juga lebih ramah lingkungan karena tidak menimbulkan polusi udara seperti yang 
ditimbulkan oleh penggunaan engine bensin (Effendi dan Khumaidi, 2018). Faktor keamanan diambil paling besar disebabkan para petani sering memaksakan kinerja mesin apabila musim panen tiba. Maka dari itu faktor keamanan paling besar yang digunakan masih aman apabila terjadi kinerja overload pada mesin ini (Sutejo et al., 2018). Kemudian hasil kupasan dengan mesin ini sangat baik, karena kulit dan biji berpisah dengan baik dan tidak ada biji yang pecah.

\section{KESIMPULAN}

Spesifikasi alat hasil rancangan: Tenaga penggerak menggunakan motor listrik $1 \mathrm{Hp}$ atau 0,745 kW dengan putaran $1420 \mathrm{rpm}$. Diameter poros $\left(d_{s}\right)=25 \mathrm{~mm}$. Diameter puli besar $D_{p}=$ 290,94 mm (12 inchi) dan diameter puli kecil $d_{p}$ $=74,6 \mathrm{~mm}$ (3 inchi). Sabuk yang dipakai adalah sabuk-V tipe B1, kecepatan sabuk (v) $=5,54 \mathrm{~m} /$ $\mathrm{s}$, panjang sabuk (L) $=1306,5 \mathrm{~mm}$, jumlah sabuk yang digunakan 1 . Kapasitas mesin yang didapatkan $\mathrm{Ka}=3,9 \mathrm{~kg} /$ menit. Hasil pengujian mesin pengupas kulit kopi basah sudah sesuai dengan desain dan secara aktual memiliki kapasitas $240 \mathrm{~kg} / \mathrm{jam}$. Biaya penggunaan listrik mesin pulper kopi adalah 4,64 Rp/kg atau $2.319,67 \mathrm{Rp} / \mathrm{hari}$. Biaya ini lebih rendah dibandingkan jika alat dioperasikan menggunakan motor bakar yang menggunakan BBM 33,87 Rp/kg atau 17.040 Rp/hari.

\section{UCAPAN TERIMA KASIH}

Penulis berterima kasih kepada Politeknik Negeri Padang atas dukungannya pada penlitian ini melalui Hibah Penelitian Terapan Pemula, kontrak no: 269/PL.9.15/PG/2020.

\section{DAFTAR PUSTAKA}

Achmad, Z. 2016. Elemen Mesin I. PT Refika Aditama, Bandung.

Amran, A.F., Munir, A.P., dan Harahap, L.A. 2017. Rancang bangun alat pengupas kulit tanduk kopi mekanis. Jurnal Rekayasa Pangan dan Pertanian, 5(1): 149-155.
Effendi, R., dan Khumaidi, M. 2018. Perancangan mesin perajang bawang serbaguna menggunakan motor listrik dengan kapasitas $55 \mathrm{~kg} / \mathrm{jam}$. Jurnal POLIMESIN, 16(2): 47-50.

Harsokusoemo, D. 2004. Pengantar Perancangan Teknik. Institut Teknologi Bandung, Bandung.

Nasution, A.Y., dan Efendi, R. 2018. Perancangan alat pengupas kopi basah dengan kapasitas $120 \mathrm{~kg} / \mathrm{jam}$. Turbo, 7(2): 140-145.

Sabani. 2018. Profil Kopi Kerinci. (Diakses dari www.sabani.com, 25 Agustus 2019).

Siswoyo. 2018. Teknik Listrik Industri Jilid 2 untuk SMK. Direktorat Pembinaan Sekolah Menengah Kejuruan, Direktorat Jenderal Manajemen Pendidikan Dasar dan Menengah, Departemen Pendidikan Nasional, Jakarta.

Sodik, A., Suharno, K., dan Widodo, S. 2016. Perancangan mesin pengupas kopi dengan menggunakan dua rol pengupas. Jurnal Wahana Ilmuwan, 1(1): 55-64.

Sonawan, H. 2010. Perancangan Elemen Mesin. Alfabeta, Bandung.

Sudirman, Y., Waluyo, S., dan Warji. 2014. Uji kinerja prototipe alat pembersih gabah. Jurnal Teknik Pertanian Lampung, 3(1): 1-8.

Sugandi, W.K., Yusuf, A., dan Thoriq, A. 2017. Rancang bangun mesin pengiris talas. Jurnal Teknik Pertanian Lampung, 6(1): 53-62.

Sularso, dan Suga, K. 1997. Dasar Perencanaan Dan Pemilihan Elemen Mesin. PT Pradnya Paramita, Jakarta.

Sutejo, A., Mardjan, S.S., Hermawan, W., Desrial. 2018. Kinerja mesin pemisah potongan tangkai dan daun teh. Jurnal Teknik Pertanian Lampung, 7(3): 160-167. 